\title{
Empirical Analysis of Context based Content Delivery for M-Learning Scenarios using ANFIS
}

\author{
Sudhindra B.Deshpande ${ }^{*}, 1$ \\ Department of Information Science \& Engineering \\ Gogte Institute of Technology \\ Belagavi, Karnataka \\ India
}

\author{
Shrinivas R.Mangalwede ${ }^{2}$ \\ Department of Computer Science \& Engineering \\ Gogte Institute of Technology \\ Belagavi, Karnataka \\ India
}

\begin{abstract}
Today's world is unusually popular with the internet and mobile devices in everyday life. It offers unprecedented possibilities learning with mobility. This kind of learning can be called "M-learning" (Mobile Learning) at any point in the world. Meeting learners ' needs in the current scenario in which collaborative electronic and mobile education systems have become more evolving. Every learners ' needs differ in terms of learning; context, content, learning styles, speed of learning, even including preferences, places. Mobile learning enables the learner to learn while moving, enabling the learner to learn in any time and any place. Learning styles have evolved along with advances in technology; specifically advances in mobile technology and mobile networks. Portable devices such as mobile phones, tabs, iPods, etc. are commonly used today by all. The way we learn has been changed with the use of these devices in education. In M-learning environment the learner has access to the contents everywhere and every time through mobile devices. Customization and learner context awareness are the important factors in providing the learner with relevant content. Appropriate content delivery based on a learner's context is a complex process. So a content delivery system is needed that takes into account learners ' needs such as context, style and devices features. To model such a system neural network with fuzzy reasoning can be used, to accommodate the dynamically changing learning styles, contexts and characteristics of smart device. "If-then" conditions can be formed to build the suggestion rules required for such a content delivery system. ANFIS i.e. Artificial Nero Fuzzy Inference System is an integral asset to create fuzzy systems with IF-THEN guidelines. To model and analyze this type of context aware and adaptive content delivery system for an M-learning environment, ANFIS can be used. In this article, use of ANFIS tool is demonstrated for various m-learning scenarios with different contexts. Four different contexts are constructed based on the inputs given by the student learners. Using ANFIS these four scenarios have been analyzed empirically for their performance based on the RMSE of various membership functions.
\end{abstract}

Keywords-Personalization; adaptive learning e-learning; distance learning; mobile learning; M-Learning; ANFIS; fuzzy system; neural networks; personalization; context awareness; content adaption; content delivery; expert system

\section{INTRODUCTION}

Learning is acquiring the knowledge through study, experience, or being taught. The traditional learning is through physical existence i.e. a teacher used to deliver lectures in classroom and through group discussions, white board or with slide projections, teaching learning process happens in classroom. To improve the learning ability, students need to ask questions, take notes and write assignments. Here learning is restricted only to books and teachers.

In recent years Internet and information technology has brought great changes into learning phenomenon. A verity of technological advancements like wireless communication and mobile devices have emerged and revolutionized the education. Education, via Internet and intelligent, portable gadgets, is one of the most interesting domains in today's world. The increasing use of computers, mobile devices and networks makes people more attractive in mobile learning. From distance learning to e-learning, and from e-learning to m-learning, has revolutionized the education with technology, reducing the constraints of space and time, reduced costs of learning, particularly increasing the learning efficiency. Applying environmental intelligence in educational scenarios allows students to immerse themselves in a digital environment that is aware of their presence and context. Mobile learning can provide new ways to deliver training, develop talent, and build a workforce with the skills and knowledge needed to meet current and future demands to enhance organizations' economic growth through mobile learning.

Learners have different cultures, education backgrounds, attentions, age, gender and social roles, and interests, making a significant difference in learning behavior. Providing the right ' content and tactics for teaching is very demanding in line with the learners ' needs. With new mobile technology, the education process must change and behave according to needs and interests of individual learner. Context-aware is a computing style in which situational and environmental information about places, people and things is used to anticipate immediate needs and to provide enriched, situationaware and usable content, functions and experiences proactively. Context awareness originated as a term derived from ubiquitous computing or as so-called pervasive computing that links environmental changes with mobile systems.

Context awareness is a mobile device property that is defined in addition to location awareness. M-Learning tries to combine the possibilities provided by new mobile technologies, wireless infrastructure and E-Learning strategies. Various definitions of M-Learning are as following.

*Corresponding Author 
1) M-Learning refers to "learning that may take place in multiple locations, across multiple times and addressing multiple content areas using static or portable equipments, such as wireless laptops, smart phones or personal media players" [1].

2) From pedagogical perspective M-Learning is defined as "any sort of learning that happens when learner is not at a fixed, predetermined location, or learning that happens when learner takes advantage of learning opportunities offered by mobile technologies" [2].

3) M-Learning is one new learning mode that users can use the mobile communication terminals to assist them to learn [3].

4) M- Learning can be defined as "the ability to learn independently without any constraint of place and time, facilitated by a range of mobile devices such as mobile phones, PDAs, iPod, pocket PCs and blackberries" [4].

For such m-learning system one more important aspect is content delivery. The formats of content should vary according to the context the learner is in. Delivery of the content depends on the context of a learner. The context may be location, time, network speed, battery and noise etc. According to the context of the learner different formats of the content need to be delivered. The formats of content may be in audio, video or text/pdf format.

To develop adaptive content delivery system, rules need to be framed. These rules can be treated as suggestions or circumstances to deliver the different format of the contents. To frame the rules, there is a need to find a technique which assist in building them; also to find the behaviour and performance. ANFIS i.e. Artificial Neural Fuzzy Inference System can be used to simulate the system; through which performance of various models and scenarios can be compared and measured.

\section{LITERATURE}

In today's society, which is considered as a Mobile Communication Society, mobile technology is also adapted in education. Qin Shuai and Zhou Ming-quan [5] in their paper propose M-Learning in cloud will have lot of opportunities. According to them adapting existing E-Learning services and didactic content to M-Learning is very much challenging in nature.

Yuan Jiugen,Xing Ruonan and Wang Jianmin [6] in their paper highlighted the importance of M-Learning in teaching. They discuss an analysis of the application of M-Learning in education in teaching with respect to learners' age and styles.

Jane Y-K and Mike Joy [7] have discussed about personalization in context aware M-Learning depending on learning preferences of learners. They have discussed varieties of scenarios of mobile learners to illustrate different $\mathrm{M}$ Learning preferences. The scenarios distinguish between different learners' preferred locations, their preferences for the levels of noise/distractions in a location and time of the day to conduct their studies. They propose that building these preferences is challenging work.
Yi Jin [8] in his paper proposes and exemplifies a framework for M-Learning platform through a layered module and he explains about eight feasible functions including course learning, teaching, collecting of content, training of mobile education, outdoor task supporting, Q\&A, blogs and games. Author concludes that there is requirement of new applied functions to be designed for existing system according to the new need of user.

Hsuan-Pu Chang [9] has proposed four modules to carry out the adaptive course caching and adaptive course presentation strategies. Author discusses about creating a package of learning material that will play on number of learning management systems.

Gwo-Jen Hwang and his co-authors [10] in their paper have investigated the effects of mobile learning model that integrates real world and digital world resources on the cognitive load and learning achievement of learners.

Fadi R.Shahroury [11] discusses in his paper that concept of data mining in academics is still at early stages and aims to highlight the potential of data mining in M-Learning and suggests various data mining tools that can be beneficial for M-Learning.

R.Madhubala and A.Ahila [12] have proposed a Context Aware and Adaptive Mobile Learning. It includes the detailed survey about context aware and adaptive m-learning, which serves as the base for new researches in this area. The system uses the clustering technique for generating adapted and personalized content for the user. Mobile learning helps the user to learn the course/subject at anytime and anywhere and also provides the unique experience to the learners in terms of its flexibility. In order to provide effective learning contents to the users, both device and learner context should be considered.

Richard A. W., et al. [13] have proposed a considering learning styles and context-awareness for mobile adaptive learning. An approach for providing mobile, personalized course content tailored to each individual's learning style while incorporating adaptive context awareness. The respective approach has been implemented as an iOS application and the evaluation with 45 students show that students were able to improve their comprehension of a subject matter by $23 \%$ after using the application.

Nikolaos, Polatidis, et al. [14] have proposed a Privacypreserving recommendation in context-aware mobile environments. It was focused on user privacy by providing a method for context privacy-preservation and privacy protection at user interface level. Thus, a set of algorithms that are part of the method has been designed with privacy protection in mind, which was done by using realistic dummy parameter creation. To demonstrate the applicability of the method, a relevant context-aware data set has been used to run performance and usability tests. The method has been experimentally evaluated using performance and usability evaluation tests and was shown that with a small decrease in terms of performance, user privacy can be protected.

Mario, Casillo, et al. [15] have proposed a Context-Aware Mobile Solution for Assisting Tourists in a Smart 
Environment It was introduced an adaptive Context Aware app able to collect not-structured data, belonging to heterogeneous sources and develop tailored recommendations for the user, in order to support a tourist inside a town. The solution found takes advantage of information technologies, like Internet of Thing and Internet of Services and the objective was reached through the use of a system of description of the context through a graphical formalism named Context Dimension Tree.

Singh, Gnana, et al. [16] have proposed a Mobile Application for m-Learning. The problem was addressed by m-learning using mobile application. In m-learning approachbased education, the course contents were uploaded to the cloud server by the teacher. Then, the students those who were not able to attend school or college can download the course content through internet using an m-learning mobile application and learn them. Once the course content was downloaded to the mobile devices through mobile application, the student can learn even without internet connectivity. This presents a mobile application for m-learning for the students those who are not able to attend the classes at engineering colleges.

Matlab ANFIS tool [17] [18] is used to demonstrate the Takagi- Sugeno fuzzy inference framework for the content delivery system.

\section{ARTIFICIAL NERO FUZZY INFERENCE SYSTEM (ANFIS)}

Takagi- Sugeno fuzzy inference framework is used in ANFIS architecture [14] which is an adaptive system that utilizes directed learning algorithm. Fig. 1 demonstrates the architecture of fuzzy reasoning component for TakagiSugeno model and ANFIS that consists of two sources of information " $\mathrm{x}$ " and " $\mathrm{x}$ ", and one yield or output " $\mathrm{f}$ ".

Takagi-Sugeno model follows the two variants of IFTHEN are:

RULE $1=$ If ' $\mathrm{x}$ ' is $\mathrm{A} 1$ and ' $\mathrm{y}$ ' is $\mathrm{B} 1$ Then $\mathrm{f} 1=\mathrm{p} 1 \mathrm{x}+\mathrm{q} 1 \mathrm{x}+\mathrm{r} 1$

RULE 2 = If ' $x$ ' is $A 2$ and ' $y$ ' is B2 Then $\mathrm{f} 2=\mathrm{p} 2 \mathrm{y}+\mathrm{q} 2 \mathrm{y}+\mathrm{r} 2$,
Where A1, A2 and B1, B2 are the membership elements of each info ' $x$ ' and ' $y$ ', while $p 1, q 1, r 1$ and $p 2, q 2, r 2$ are linear parameters to a limited extent Then (subsequent part) of Takagi-Sugeno fuzzy inference model.

Referring to Fig. 1, ANFIS architecture shows five layers. The first layer and fourth layer consist of adaptive nodes, while the remaining layers consist of fixed nodes.ANFIS tool in MATLAB provides Grid partitioning algorithm. The algorithm generates a single-output Sugeno-type FIS by using grid partitioning on the data.

genfisl generates a Sugeno-type FIS structure used as initial conditions (initialization of the membership function parameters) for ANFIS training. It generates input membership functions by uniformly partitioning the input variable ranges, and creates a single-output Sugeno fuzzy system. The fuzzy rule base contains one rule for each input membership function combination.

ANFIS tool simulates and generates Root Mean Square Error (RMSE) values for data sets which include training, cheking and testing. It also facilitates to use various membership functions.

Membership function is a curve that defines how each point in the input space is mapped to a membership value (or degree of membership) between 0 and 1 . They characterize fuzziness whether the elements in fuzzy sets are discrete or continuous. The membership functions trimf, trapmf, gaussmf, gauss $2 \mathrm{mf}$ and gbellmf are explained below:

1) Triangular function: defined by a lower limit a, an upper limit $\mathrm{b}$, and a value $\mathrm{m}$, where $\mathrm{a}<\mathrm{m}<\mathrm{b}$, as given by equation (1).

$\mu_{A}(x)=\left\{\begin{array}{cc}0 & x \leq a \\ \frac{x-a}{m-a}, & a<x \leq m \\ \frac{b-x}{b-m}, & m<x<b \\ 0 & x \geq b\end{array}\right.$

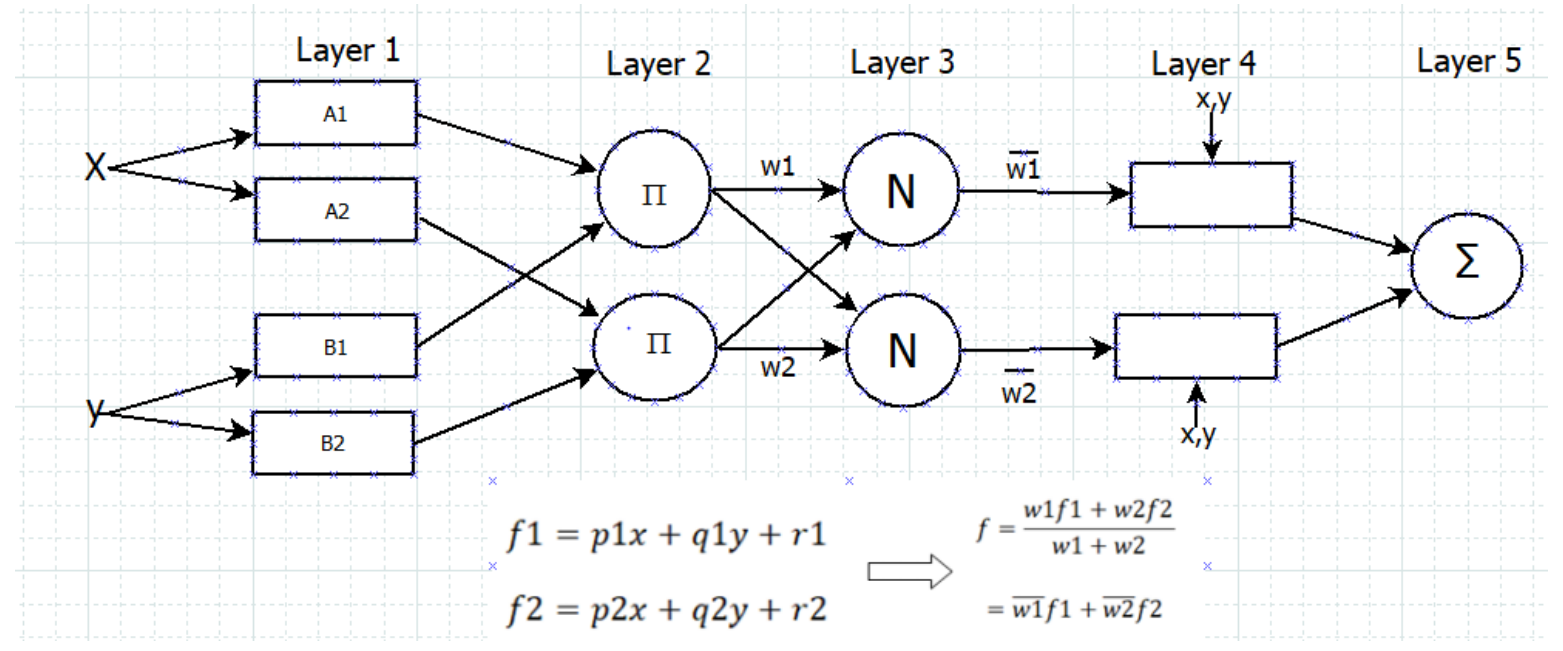

Fig. 1. Architecture of ANFIS with 5 Layers. 


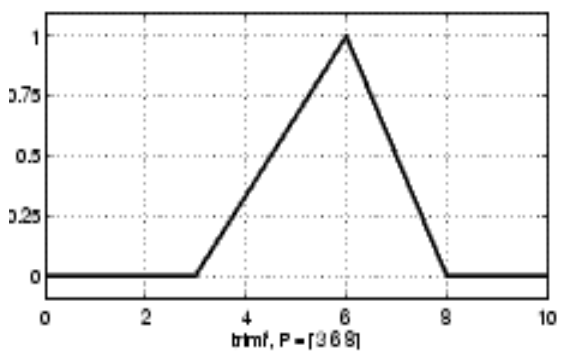

Fig. 2. Triangular Membership Function Curve.

The simplest is the triangular membership function is shown in Fig. 2, and it has the function name trimf. It's nothing more than a collection of three points forming a triangle.

2) Trapezoidal function: defined by a lower limit a, an upper limitd, as given by equation (2).

$\mu_{A}(x)=\left\{\begin{array}{cc}0, \quad(x<a) \text { or }(x>d) \\ \frac{x-a}{b-a}, \quad a \leq x \leq b \\ 1, \quad b \leq x \leq c \\ \frac{d-x}{d-c}, \quad c \leq x \leq d\end{array}\right.$

Fig. 3 shows the trapezoidal membership function, where a lower support limit b, and an upper support limit c, where a < $\mathrm{b}<\mathrm{c}<\mathrm{d}$. The trapezoidal membership function, trapmf, has a flat top and really is just a truncated triangle curve.

3) Gaussian function: defined by a central value $m$ and a standard deviation $\mathrm{k}>0$, as given by equation (3)

$\mu_{A}(x)=e^{-\frac{(x-m)^{2}}{2 k^{2}}}$

The smaller $\mathrm{k}$ is, the narrower the "bell" is. This gaussmf, is built on the Gaussian distribution curve: a simple Gaussian curve as depicted in Fig.4.

4) The second gaussian function: depends on two parameters sig and $c$ as given by equation (4).

$f(x ; \sigma, c)=e^{-\frac{(x-c)^{2}}{2 \sigma^{2}}}$

The function gauss $2 \mathrm{mf}$ is a combination of two of these two parameters as shown in Fig. 5; two-sided composite of two different Gaussian curves. The first function, specified by sigl and $c 1$, determines the shape of the left-most curve. The second function specified by sig2 and $c 2$ determines the shape of the right-most curve. Whenever $c 1<c 2$, the gauss $2 \mathrm{mf}$ function reaches a maximum value of 1 . Otherwise, the maximum value is less than one. The parameters are listed in the order.

5) The generalized bell function: gbellmf, depends on three parameters $a, b$, and $c$ as given by equation (5), where the parameter $b$ is usually positive and the parameter $c$ locates the center of the curve as shown in Fig. 6 .

$f(x ; a, b, c)=\frac{1}{1+\left|\frac{x-c}{a}\right|^{2 b}}$

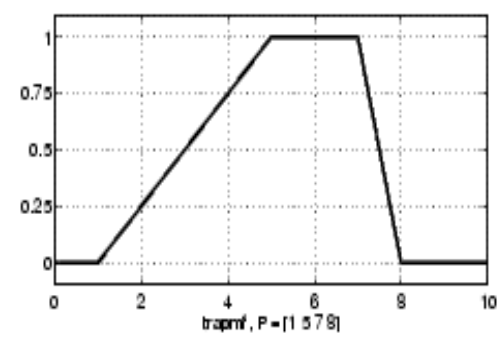

Fig. 3. Trapezoidal Membership Function Curve.

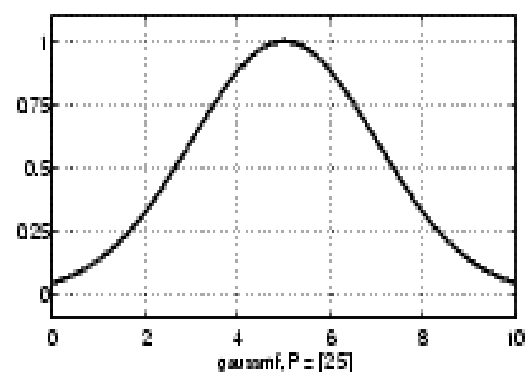

Fig. 4. Gaussian Distribution Curve.

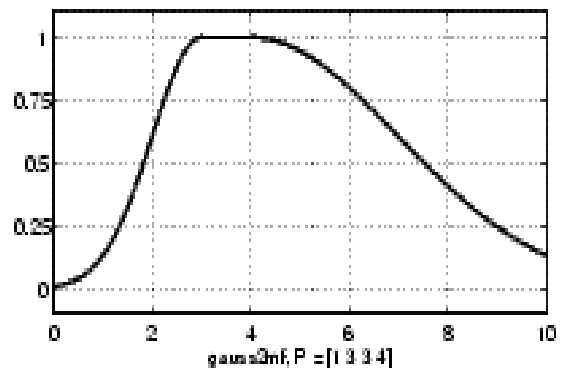

Fig. 5. Gauss2mf Function Curve.

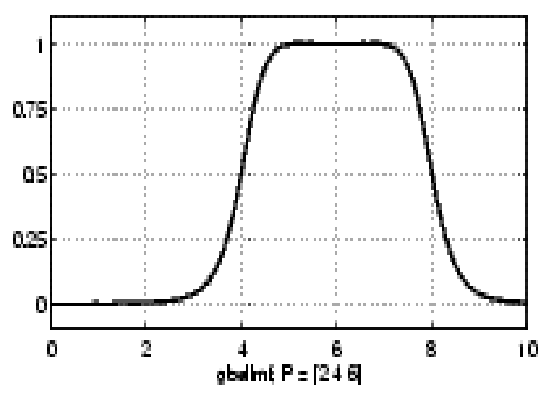

Fig. 6. Generalized Bell Function Curve.

\section{PROPOSED MODEL}

In this article, four different context aware m-learning scenarios under different circumstances have been modeled. The context relative information has been collected in real time where 700 engineering students participated. Engineering students of branches Computer Science, Information Science, Electrical, Electronic and Mechanical have participated and data is collected through Google forms. 
Students have answered various questionnaires related to their contexts, device characteristics and format of the contents that they are interested. The questionnaires are related to the following questions:

- Preferences of and within locations - home, college, etc.

- Personal factors like - friends, likes to be alone, in a group.

- Whether a student likes audio, video, text/pdf in learning.

- What time student prefers to study for the time of the day- daytime, morning, afternoon, evening, night, midnight?

The content delivery is adaptable with preferred contexts, entered by the students. Fig. 7 depicts the general architecture of the adaptive content delivery system.

The four scenarios deal with different contexts. All the scenarios generally have the domains: Preferred Location, Preferred Timing, Preferred Content Type, Noise, Network Speed and Battery Level. Each domain in turn has attributes that takes different values.

\section{A. Scenario I}

In this model, data pertaining to home context is collected, as shown in Fig. 8.

\section{B. Scenario II}

Here, data pertaining to home context is collected with addition to noise, as shown in Fig. 9.

\section{Scenario III}

Here, data with respect to the college context is collected, as shown in Fig. 10.

\section{Scenario IV}

Here, data is collected considering both contexts home and college, as shown in Fig. 11.

ANFIS is used to analyze all the four scenarios separately. Firstly, the data collected from the students, is partitioned into training dataset and checking dataset and further divided in four groups (training dataset \%: checking dataset \%) as 50:50, $60: 40,70: 30$ and 80:20, respectively. Secondly the behavior of these groups is measured with the five membership function: trimf, trapmf, gaussmf, gauss $2 \mathrm{mf}$ and gbellmf. The grid partitioning algorithm is used as the number of input variables are in the range of 4 to 5 . Further with respect to each group and with respect each membership function, the RMSEs are generated. Lastly the average RMSE is calculated for each membership function generated with respect to all the four groups of datasets. And the average RMSEs are compared and the membership function with the least RMSE is considered as the better performing result.

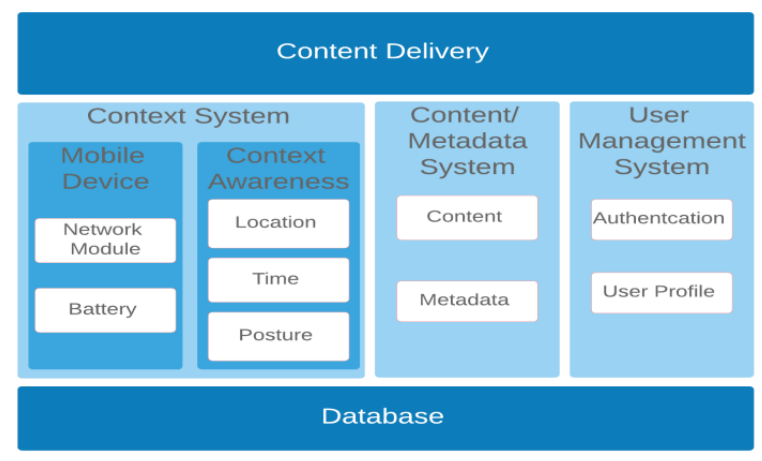

Fig. 7. Working Model of Adaptive Content Delivery Context System.

Scenario I : HOME

Fig. 8. Home Scenario I.

\begin{tabular}{|c|c|}
\hline \multicolumn{2}{|c|}{ Scenario II : HOME(NOISE) } \\
\hline Location: & Room,Hall,Gallery \\
\hline Timing: & Moming,Aftemoon,Evening,Night \\
\hline Network: & $2 g, 3 g, 4 g$ \\
\hline Battery: & Low,Average,High \\
\hline Noise: & Alone,Friends \\
\hline Content Format: & Audio,Text/pdf,Video \\
\hline
\end{tabular}

Fig. 9. Home Scenario II.

Location: Scenario III : COLLGGE

Fig. 10. College Scenario III. 


\begin{tabular}{|c|c|}
\hline \multicolumn{2}{|c|}{ Scenario IV : HOME \& COLLEGE } \\
\hline Location:HOME & Room,Hall,Gallery \\
\hline Location:COLLEGE & Classroom,Library,Campus \\
\hline Timing: & Morming,Aftemoon,Evening,Night \\
\hline Network: & $2 g, 3 g, 4 g, w i f i$ \\
\hline Battery: & Low,Average,High \\
\hline Noise: & Alone,Friends \\
\hline Content Format: & Audio,Text/pdf, Video \\
\hline
\end{tabular}

Fig. 11. College and Home Scenario IV.

\section{RESULTS AND DISCUSSION}

In this section, four different scenarios have been simulated using ANFIS.

\section{A. Scenario I}

In this approach the context of home is considered. The student learners have given the various preferences to study. The study material i.e. content will be delivered in text/pdf, or audio or video format in association with the context preferred and device characteristics at that moment. The attributes and their values are given as:

Location $($ Home $)=\{$ room, hall, gallery $\}$

Timing $=\{$ morning, afternoon, evening,night $\}$

Network $=\{2 \mathrm{~g}, 3 \mathrm{~g}, 4 \mathrm{~g}\}$

Battery $=\{$ low, average, high $\}$

Content $=\{$ text/pdf, audio, video $\}$

The suggestion rules are constructed based on the inputs given by the student learners; are in the format of IF-ANDTHEN rules, for example:

IF Location(Home)='room' AND Timing='morning' AND Network='3g' AND Battery='low' THEN Content='audio'
IF Location(Home)='room' AND Timing='night' AND

Network='4g' AND Battery='average' THEN

Content='video'

IF Location(Home)='hall' AND Timing='afternoon' AND Network='3g' AND Battery='high' THEN Content='video'

IF Location(Home)='gallery' AND Timing='evening' AND Network='4g' AND Battery='average' THEN Content='text/pdf'

Fig. 12 depicts the ANFIS structure with $3 * 4 * 3 * 3$ input membership functions.

Table I shows the performance behavior of the scenario I where RMSEs of the trimf,trapmf,gbellmf,gaussmf and gauss $2 \mathrm{mf}$ are generated and compared. Out of five mf types, trimf gives 0.87 and gbellmf gives 0.90 with better performance. And remaining trapmf, gaussmf and gauss $2 \mathrm{mf}$ give $>1$, which are with poor performance. But overall trimf with $\mathrm{RMSE}=0.87$ performs well in comparison with others as depicted in Fig. 13.

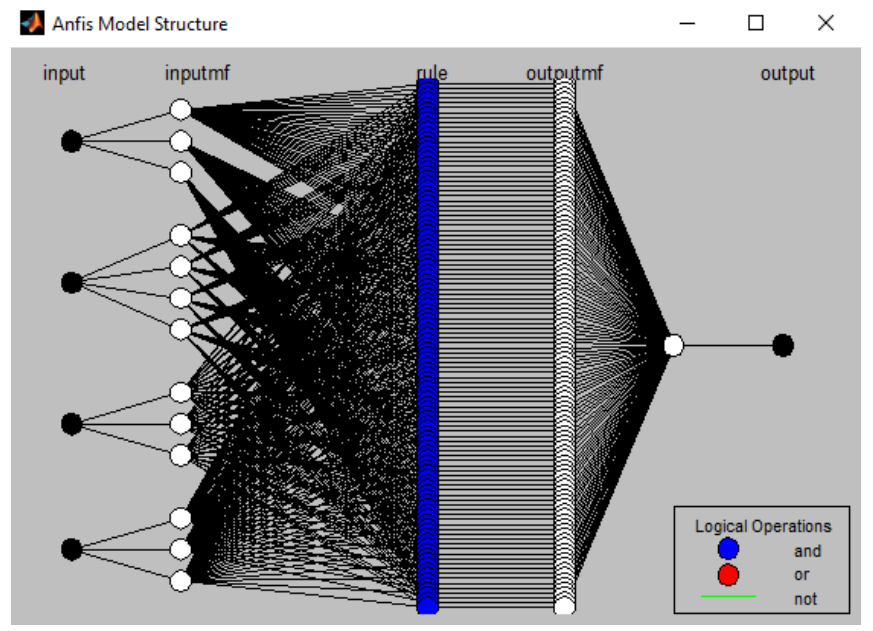

Fig. 12. ANFIS Structure with $3 * 4 * 3 * 3$ Input mfs Scenario 1 .

TABLE. I. PERFORMANCE BEHAVIOR OF VARIOUS MF TYPES FOR SCENARIO I

\begin{tabular}{|c|c|c|c|c|c|c|c|c|c|c|c|c|c|}
\hline \multicolumn{4}{|c|}{ Number of fuzzy rules } & \multicolumn{10}{|c|}{$108(3 * 4 * 3 * 3)$} \\
\hline \multicolumn{4}{|c|}{ Total Number of Data Set } & \multicolumn{10}{|l|}{408} \\
\hline \multicolumn{4}{|c|}{ Membership Functions } & \multicolumn{2}{|l|}{ trimf } & \multicolumn{2}{|c|}{ Trapmf } & \multicolumn{2}{|c|}{ gbellmf } & \multicolumn{2}{|c|}{ Gaussmf } & \multicolumn{2}{|c|}{ gauss2mf } \\
\hline $\begin{array}{l}\text { Training } \\
\text { set }(\%) \text { : } \\
\text { checking } \\
\text { set }(\%)\end{array}$ & $\begin{array}{l}\text { Number } \\
\text { of } \\
\text { training } \\
\text { data } \\
\text { pairs }\end{array}$ & $\begin{array}{l}\text { Number } \\
\text { of } \\
\text { checking } \\
\text { data } \\
\text { pairs }\end{array}$ & $\begin{array}{l}\text { Training } \\
\text { RMSE }\end{array}$ & epoch & $\begin{array}{l}\text { Checking } \\
\text { RMSE }\end{array}$ & epoch & $\begin{array}{l}\text { Checking } \\
\text { RMSE }\end{array}$ & epoch & $\begin{array}{l}\text { Checking } \\
\text { RMSE }\end{array}$ & Epoch & $\begin{array}{l}\text { Checking } \\
\text { RMSE }\end{array}$ & epoch & $\begin{array}{l}\text { Checking } \\
\text { RMSE }\end{array}$ \\
\hline $50: 50$ & 204 & 204 & 0.788 & 5 & 0.80 & 10 & 1.261 & 15 & 1.226 & 20 & 1.39 & 20 & 1.39 \\
\hline 60:40 & 245 & 163 & 0.794 & 5 & 0.920 & 10 & 1.543 & 15 & 0.788 & 20 & 1.039 & 20 & 1.085 \\
\hline 70:30 & 286 & 122 & 0.791 & 5 & 0.995 & 10 & 0.952 & 15 & 0.824 & 20 & 1.091 & 20 & 1.063 \\
\hline $80: 20$ & 326 & 82 & 0.802 & 5 & 0.787 & 10 & 1.175 & 15 & 0.781 & 20 & 1.0383 & 20 & 1.155 \\
\hline \multicolumn{3}{|l|}{ Average } & 0.793 & & 0.875 & & 1.232 & & 0.904 & & 1.13 & & 1.17 \\
\hline
\end{tabular}




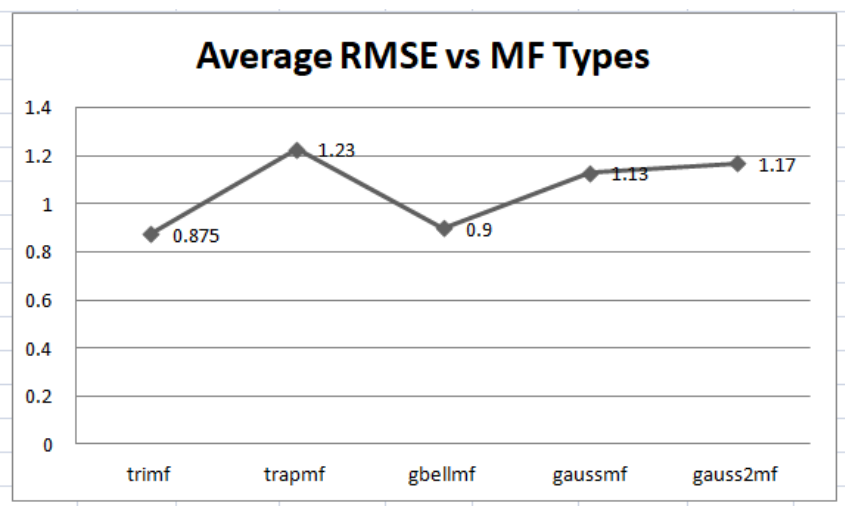

Fig. 13. Average RMSEs of Scenario I against Various MF Types.

\section{B. Scenario II}

In this approach the context of home with noise is considered. The student learners have given the preferences to study with additional attribute noise; whether learner wants to study alone or with friends. When with friends, generally it can be considered as discussion i.e. noisy environment. For the network attribute, additional 'wifi' value has been also added in this scenario. The study material i.e. content will be delivered in text/pdf, or audio or video format in association with the context and noise preferred and device characteristics at that moment. The attributes and their values are given as below:

Location $($ Home $)=\{$ room, hall, gallery $\}$

Timing $=\{$ morning, afternoon, evening,night $\}$

Noise $=\{$ alone, friends $\}$

Network $=\{2 \mathrm{~g}, 3 \mathrm{~g}, 4 \mathrm{~g}$, wifi $\}$

Battery $=\{$ low, average,high $\}$

Content $=\{$ text/pdf, audio, video $\}$

The suggestion rules are constructed based on the inputs given by the student learners; are in the format of IF-ANDTHEN rules, for example:

IF Location(Home)='room' AND Timing='morning' AND Noise='alone' AND Network='3g' AND Battery='average' THEN Content='text/pdf'

IF Location(Home)='hall' AND Timing='afternoon' AND Noise='friends' AND Network='4g' AND Battery='high' THEN Content='video'

IF Location(Home)='room' AND Timing='evening' AND Noise='alone' AND Network='4g' AND Battery='low' THEN Content='audio'

IF Location(Home)='gallery' AND Timing='evening' AND Noise='friends' AND Network='wifi' AND

Battery='average' THEN Content='audio'

IF Location(Home)='room' AND Timing='night' AND

Noise='friends' AND Network='2g' AND Battery='average' THEN Content='audio'

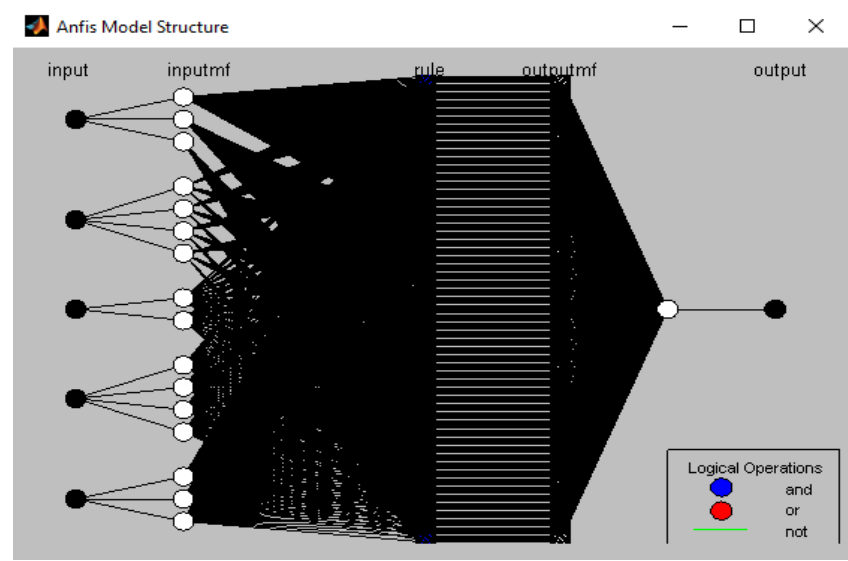

Fig. 14. ANFIS Structure with $3 * 4 * 2 * 4 * 3$ Input mfs - scenario II.

Fig. 14 depicts the ANFIS structure with $3 * 4 * 2 * 4 * 3$ input membership functions.

Table II summarizes the performances of the scenario 2 where RMSEs of the trimf,trapmf,gbellmf,gaussmf and gauss $2 \mathrm{mf}$ are generated and compared. Out of five mf types, trimf gives 0.77 , gbellmf gives 0.94 and gauss $2 \mathrm{mf}$ gives 0.85 . And remaining trapmf and gaussmf give $>1$, performing poorly. But overall trimf with $\mathrm{RMSE}=0.77$ performs well in comparison with others as depicted in Fig. 15.

\section{Scenario III}

In this approach the context of college is considered. The student learners have given the preferences to study in college. The study material i.e. content will be delivered in text/pdf, or audio or video format in association with the context and device characteristics at that moment. The attributes and their values are given as below:

Location $($ College $)=\{$ classroom,library,campus $\}$

Timing $=\{$ morning, afternoon, evening,night $\}$

Network $=\{$ wifi, $4 \mathrm{~g}\}$

Battery $=\{$ average, high $\}$

Noise $=\{$ alone, friends $\}$

Content $=\{$ text/pdf, audio, video $\}$

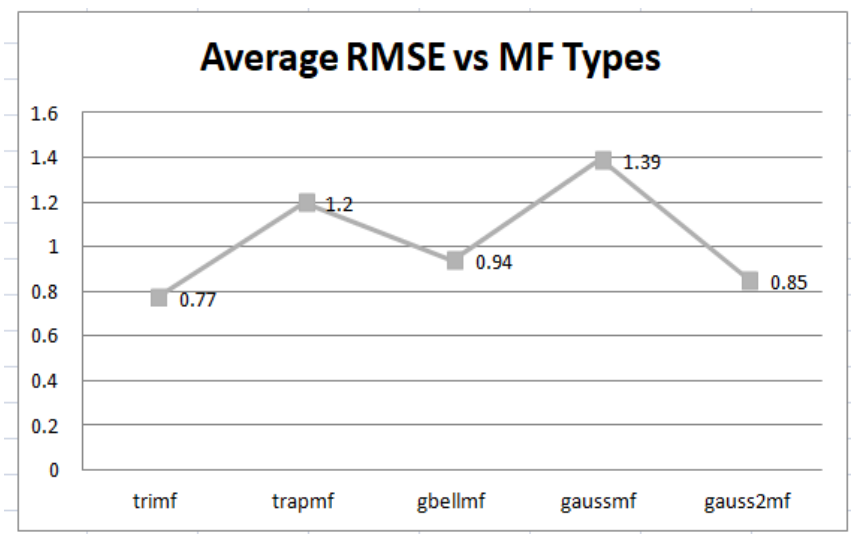

Fig. 15. Average RMSEs of Scenario II against Various MF Types. 
TABLE. II. PERFORMANCE BEHAVIOR OF VARIOUS MF TyPES FOR SCENARIO II

\begin{tabular}{|c|c|c|c|c|c|c|c|c|c|c|c|c|c|}
\hline \multicolumn{4}{|c|}{ Number of fuzzy rules } & \multicolumn{10}{|c|}{$288(3 * 4 * 2 * 4 * 3)$} \\
\hline \multicolumn{4}{|c|}{ Total Number of Data Set } & \multicolumn{10}{|l|}{510} \\
\hline \multicolumn{4}{|c|}{ MF Types } & \multicolumn{2}{|l|}{ trimf } & \multicolumn{2}{|c|}{ trapmf } & \multicolumn{2}{|c|}{ gbellmf } & \multicolumn{2}{|c|}{ gaussmf } & \multicolumn{2}{|c|}{ gauss2mf } \\
\hline $\begin{array}{l}\text { traning } \\
\text { set }(\%) \text { : } \\
\text { checking } \\
\text { set }(\%)\end{array}$ & $\begin{array}{l}\text { Number } \\
\text { of } \\
\text { training } \\
\text { data } \\
\text { pairs } \\
\end{array}$ & $\begin{array}{l}\text { Number } \\
\text { of } \\
\text { checking } \\
\text { data } \\
\text { pairs }\end{array}$ & $\begin{array}{l}\text { Training } \\
\text { RMSE }\end{array}$ & epoch & $\begin{array}{l}\text { Checking } \\
\text { RMSE }\end{array}$ & epoch & $\begin{array}{l}\text { Checking } \\
\text { RMSE }\end{array}$ & epoch & $\begin{array}{l}\text { Checking } \\
\text { RMSE }\end{array}$ & epoch & $\begin{array}{l}\text { Checking } \\
\text { RMSE }\end{array}$ & epoch & $\begin{array}{l}\text { Checking } \\
\text { RMSE }\end{array}$ \\
\hline $50: 50$ & 255 & 255 & 0.68 & 5 & 0.867 & 10 & 1.588 & 15 & 1.022 & 20 & 1.408 & 20 & 1.129 \\
\hline $60: 40$ & 306 & 204 & 0.686 & 5 & 0.844 & 10 & 1.716 & 15 & 0.694 & 20 & 0.855 & 20 & 0.695 \\
\hline $70: 30$ & 357 & 153 & 0.679 & 5 & 0.67 & 10 & 0.814 & 15 & 0.977 & 20 & 1.549 & 20 & 0.689 \\
\hline $80: 20$ & 408 & 102 & 0.669 & 5 & 0.703 & 10 & 0.693 & 15 & 1.105 & 20 & 1.755 & 20 & 0.922 \\
\hline Average & & & 0.678 & & 0.771 & & 1.202 & & 0.949 & & 1.391 & & 0.858 \\
\hline
\end{tabular}

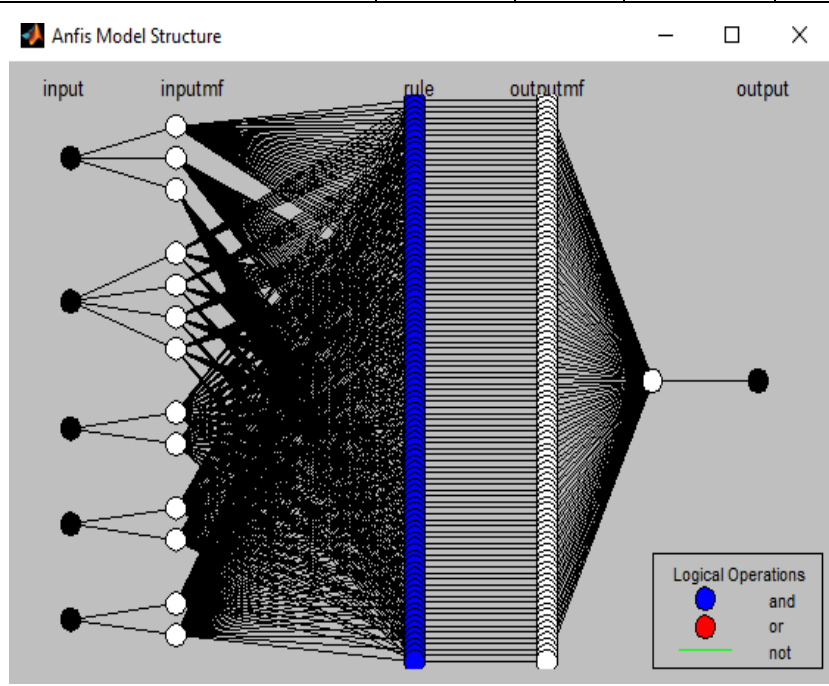

Fig. 16. ANFIS Structure with $3 * 4 * 2 * 2 * 2$ Input MFS - Scenario III.

Fig. 16 depicts the ANFIS structure with $3 * 4 * 2 * 2 * 2$ input membership functions.

Table III provides the performances of the scenario III where RMSEs of the trimf,trapmf,gbellmf,gaussmf and gauss $2 \mathrm{mf}$ are generated and compared. Out of five mf types trapmf with RMSE $=0.96$ performs better. And remaining $\mathrm{mf}$ types give $>1$, performing poorly. Fig. 17 shows the comparison of all mfs.

\section{Scenario IV}

In this scenario the both the contexts- home and college are considered. The student learners have given the preferences to study in home and as well at college. The attributes and all corresponding values of Scenarios I, II, and III are taken into consideration. The study material i.e. content will be delivered in text/pdf, or audio or video format in association with the contexts and device characteristics at that moment. The attributes and their values are given as below:

Location $($ College $)=\{$ classroom,library, campus $\}$ (Home $)=\{$ room,hall,gallery

Network $=\{2 \mathrm{~g}, 3 \mathrm{~g}, 4 \mathrm{~g}$, wifi $\}$

Timing $=\{$ morning, afternoon, evening,night $\}$
Battery $=\{$ low, average, high $\}$

Noise $=\{$ alone, friends $\}$

Content $=\{$ text/pdf, audio, video $\}$

Table IV provides the performances of the scenario 4 where RMSEs of the trimf,trapmf,gbellmf,gaussmf and gauss $2 \mathrm{mf}$ are generated and compared. Out of five mf types, trapmf $=0.78$, gbellmf $=0.80$ and gaussmf $=0.81$ perform better with least RMSE values. And remaining mf types give $>1$, performing poorly. Trapmf with RMSE $=0.78$ performs much well, as Fig. 18 shows the comparison of all $\mathrm{mfs}$.

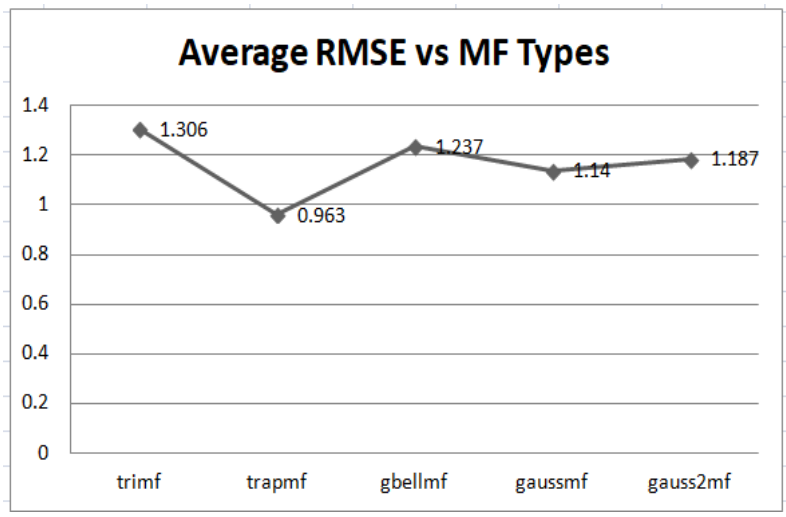

Fig. 17. Average RMSEs of Scenario III against Various MF Types.

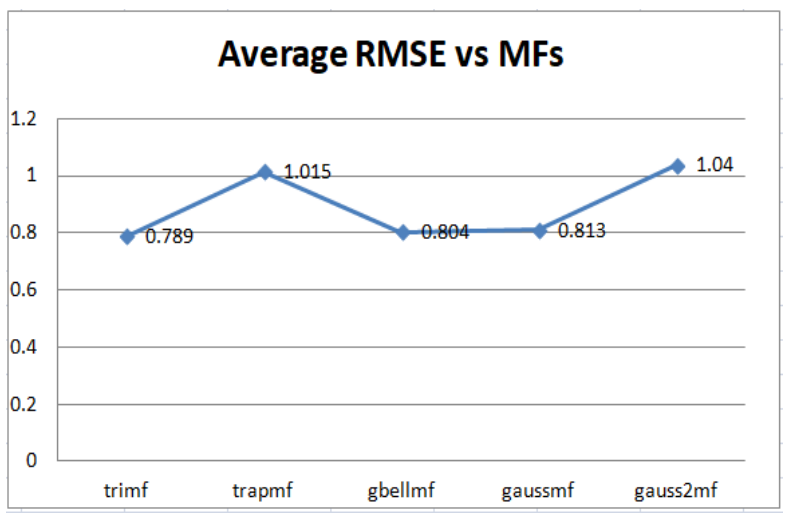

Fig. 18. Average RMSEs of Scenario IV against Various MF Types. 
TABLE. III. PERFORMANCE BEHAVIOR OF VARIOUS MF TYPES FOR SCENARIO III

\begin{tabular}{|c|c|c|c|c|c|c|c|c|c|c|c|c|c|}
\hline \multicolumn{4}{|c|}{ Number of fuzzy rules } & \multicolumn{10}{|c|}{$288(3 * 4 * 2 * 2 * 2)$} \\
\hline \multicolumn{4}{|c|}{ Total Number of Data Set } & \multicolumn{10}{|l|}{240} \\
\hline \multicolumn{4}{|c|}{ MF Types } & \multicolumn{2}{|l|}{ trimf } & \multicolumn{2}{|c|}{ trapmf } & \multicolumn{2}{|c|}{ gbellmf } & \multicolumn{2}{|c|}{ gaussmf } & \multicolumn{2}{|c|}{ gauss2mf } \\
\hline $\begin{array}{l}\text { Training } \\
\text { set }(\%) \text { : } \\
\text { checking } \\
\text { set }(\%)\end{array}$ & $\begin{array}{l}\text { Number } \\
\text { of } \\
\text { training } \\
\text { data } \\
\text { pairs }\end{array}$ & $\begin{array}{l}\text { Number } \\
\text { of } \\
\text { checking } \\
\text { data } \\
\text { pairs }\end{array}$ & $\begin{array}{l}\text { Training } \\
\text { RMSE }\end{array}$ & epoch & $\begin{array}{l}\text { Checking } \\
\text { RMSE }\end{array}$ & epoch & $\begin{array}{l}\text { Checking } \\
\text { RMSE }\end{array}$ & epoch & $\begin{array}{l}\text { Checking } \\
\text { RMSE }\end{array}$ & epoch & $\begin{array}{l}\text { Checking } \\
\text { RMSE }\end{array}$ & epochs & $\begin{array}{l}\text { Checking } \\
\text { RMSE }\end{array}$ \\
\hline $50: 50$ & 120 & 120 & 0.801 & 5 & 1.211 & 10 & 1.319 & 15 & 1.233 & 20 & 1.256 & 20 & 1.318 \\
\hline $60: 40$ & 144 & 96 & 0.80 & 5 & 1.63 & 10 & 0.831 & 15 & 0.887 & 20 & 0.902 & 20 & 0.9435 \\
\hline $70: 30$ & 168 & 72 & 0.816 & 5 & 1.509 & 10 & 0.824 & 15 & 1.271 & 20 & 0.824 & 20 & 0.824 \\
\hline $80: 20$ & 192 & 48 & 0.812 & 5 & 0.877 & 10 & 0.881 & 15 & 1.557 & 20 & 1.579 & 20 & 1.665 \\
\hline \multicolumn{3}{|l|}{ Average } & 0.807 & & 1.306 & & 0.963 & & 1.237 & & 1.140 & & 1.187 \\
\hline
\end{tabular}

TABLE. IV. PERFORMANCE BEHAVIOR OF VARIOUS MF TyPES FOR SCENARIO IV

\begin{tabular}{|c|c|c|c|c|c|c|c|c|c|c|c|c|c|}
\hline \multicolumn{4}{|c|}{ Number of fuzzy rules } & \multicolumn{10}{|c|}{$576(6 * 4 * 4 * 3 * 2)$} \\
\hline \multicolumn{4}{|c|}{ Total Number of Data Set } & \multicolumn{10}{|l|}{660} \\
\hline \multicolumn{4}{|c|}{ MF Types } & \multicolumn{2}{|l|}{ trimf } & \multicolumn{2}{|c|}{ trapmf } & \multicolumn{2}{|c|}{ gbellmf } & \multicolumn{2}{|c|}{ gaussmf } & \multicolumn{2}{|c|}{ gauss $2 \mathrm{mf}$} \\
\hline $\begin{array}{l}\text { Training } \\
\text { set }(\%) \text { : } \\
\text { checking } \\
\text { set }(\%)\end{array}$ & $\begin{array}{l}\text { Number } \\
\text { of } \\
\text { training } \\
\text { data } \\
\text { pairs }\end{array}$ & $\begin{array}{l}\text { Number } \\
\text { of } \\
\text { checking } \\
\text { data } \\
\text { pairs }\end{array}$ & $\begin{array}{l}\text { Training } \\
\text { RMSE }\end{array}$ & epoch & $\begin{array}{l}\text { Checking } \\
\text { RMSE }\end{array}$ & epoch & $\begin{array}{l}\text { Checking } \\
\text { RMSE }\end{array}$ & epoch & $\begin{array}{l}\text { Checking } \\
\text { RMSE }\end{array}$ & epoch & $\begin{array}{l}\text { Checking } \\
\text { RMSE }\end{array}$ & epoch & $\begin{array}{l}\text { Checking } \\
\text { RMSE }\end{array}$ \\
\hline $50: 50$ & 330 & 330 & 0.687 & 5 & 0.927 & 10 & 1.765 & 15 & 0.924 & 20 & 0.865 & 20 & 1.711 \\
\hline $60: 40$ & 396 & 264 & 0.708 & 5 & 0.709 & 10 & 0.707 & 15 & 0.69 & 20 & 0.7 & 20 & 0.707 \\
\hline $70: 30$ & 462 & 198 & 0.758 & 5 & 0.743 & 10 & 0.715 & 15 & 0.766 & 20 & 0.766 & 20 & 0.765 \\
\hline $80: 20$ & 528 & 132 & 0.766 & 5 & 0.78 & 10 & 0.875 & 15 & 0.838 & 20 & 0.924 & 20 & 0.977 \\
\hline \multicolumn{3}{|l|}{ Average } & 0.729 & & 0.789 & & 1.015 & & 0.804 & & 0.813 & & 1.04 \\
\hline
\end{tabular}

TABLE. V. All Scenarios with Average Training and CheCKing RMSES

\begin{tabular}{|c|c|c|c|c|c|c|}
\hline \multirow{2}{*}{ Scenarios } & \multirow{2}{*}{$\begin{array}{l}\text { Average Training } \\
\text { RMSE }\end{array}$} & \multicolumn{5}{|c|}{ Average Checking RMSE } \\
\hline & & trimf & trapmf & gbellmf & gaussmf & gauss $2 \mathrm{mf}$ \\
\hline Scenario 1 & 0.793 & 0.875 & 1.232 & 0.904 & 1.13 & 1.17 \\
\hline Scenario 2 & 0.678 & 0.771 & 1.202 & 0.949 & 1.391 & 0.858 \\
\hline Scenario 3 & 0.807 & 1.306 & 0.963 & 1.237 & 1.140 & 1.187 \\
\hline Scenario 4 & 0.729 & 0.789 & 1.015 & 0.804 & 0.813 & 1.04 \\
\hline
\end{tabular}

Table $\mathrm{V}$ refers to all above scenarios and presents the average training RMSEs and Average Checking RMSEs of all mf types.

\section{Observations:}

1) For Scenario I: trimf membership function performs well.

2) For Scenario II: trimf membership function performs well.

3) For Scenario III: trapmf membership function performs well.

4) For Scenario IV: trimf membership function performs well.
5) Overall impression 1: Scenario III gives very poor performance compared to all others; suggestion rules built for this scenario poorly perform.

6) Overall impression 2: Scenario II performance is better in comparison with Scenario I.

7) Overall impression 3: Scenario IV performs best.

The rules constructed for Scenario IV, that considers the data of both contexts home and college (refer Fig. 12) are more precise giving good performance when compared to all other scenarios in providing the adaptive content delivery based on the context. The simulation of Scenario IV using ANFIS gives comparatively better RMSE when compared to all others. 


\section{CONCLUSION}

M-learning, learn while on move, is the revolutionized education concept with increased mobility and technology advancements. To deal with mobile learning, there is a need to understand the context of various learners. According to the context preferences- like place, timing, network speed, battery level etc., there is requirement to deliver the content. The content delivery should be adaptable based on the preferences given by the learners. In this paper, four such different mlearning scenarios have been identified. Finding out of the performance of these scenarios, and which one performs best is the work behind this paper. ANFIS i.e. artificial neuro fuzzy inference model is used to simulate all the four scenarios. Individual scenarios are compared within themselves using five membership types - trimf, trapmf, gbellmf, gaussmf and gauss $2 m f$. And based on RMSEs which membership type performs well has been identified for each scenario. At the end, comparison of all the four scenarios has been made to find out which scenario performs best. And it has found that trimf (triangular membership function) performs mostly well in all four scenarios with least RMSEs. And Scenario III gives very poor performance compared to all others; Scenario II performance is better in comparison with Scenario I and Scenario IV performs the best.

\section{REFERENCES}

[1] Yuan Jiugen, Xing Ruonan, Wang Jianmin : “Applying Research of Mobile Learning Mode in Teaching", International Forum on Information Technology and Applications (IFITA), Volume: 3, Pages: $417-420,2010$.

[2] Yau, J.Y.-K. , Joy, M. "A Context-Aware Personalized M-learning Application Based on M-Learning Preferences", The 6th IEEE International Conference on Wireless, Mobile and Ubiquitous Technologies in Education (WMUTE), Page(s): 11 - 18,2010.

[3] Yi Jin : "Research of One Mobile Learning System", International Conference on Wireless Networks and Information Systems,( WNIS '09) , Pages: 162 - 165 , 2009.

[4] Fadi R.S.: "Data Mining in M-Learning Domain", Trends in Innovative Computing-Information Retrieval and Data Mining, http://www. mirlabs.net/ict12/download/Paper11.pdf, 2012.
[5] Qin Shuai, Zhou Ming-Quan: "Cloud Computing Promotes the Progress of M-Learning", International Conference on Uncertainty Reasoning and Knowledge Engineering (URKE), Volume: 2, Pages: 162 - 164, 2011.

[6] Yuan Jiugen , Xing Ruonan, Wang Jianmin : "Applying Research of Mobile Learning Mode in Teaching", International Forum on Information Technology and Applications (IFITA), Volume: 3, Pages: $417-420,2010$.

[7] Yau, J.Y.-K., Joy, M.: "A Context-Aware Personalized M-learning Application Based on M-Learning Preferences", The 6th IEEE International Conference on Wireless, Mobile and Ubiquitous Technologies in Education (WMUTE), Page(s): 11 - 18, 2010.

[8] Yi Jin : "Research of One Mobile Learning System", International Conference on Wireless Networks and Information Systems, ( WNIS '09) , Pages: 162 - $165,2009$.

[9] Hsuan-Pu Chang "Applying Adaptive Course Caching and Presentation Strategies in M-Learning Environment" , IEEE International Conference on Industrial Engineering and Engineering Management (IEEM), Pages: $1314-1318,2010$.

[10] Gwo-Jen Hwang, Wan-Ling Kuo , Po-Han Wu ,Yueh-Min Huang, YaYan Zhuang: 'An Investigation on Students' Cognitive Load and Learning Achievements for Participating in a Local Culture Mobile Learning Activity", 6th IEEE International Conference on Wireless, Mobile and Ubiquitous Technologies in Education (WMUTE), Pages: $27-33,2010$.

[11] Fadi R.S.: "Data Mining in M-Learning Domain", Trends in Innovative Computing-Information Retrieval and Data Mining, http://www. mirlabs.net/ict12/download/Paper11.pdf, 2012.

[12] Madhubala, R., and A. Akila. "Context Aware and Adaptive Mobile Learning: A Survey." Advances in Computational Sciences and Technology 10.5 (2017): 1355-1370.

[13] Tortorella, Richard AW, and Sabine Graf. "Considering learning styles and context-awareness for mobile adaptive learning." Education and Information Technologies 22.1 (2017): 297-315.

[14] Polatidis, Nikolaos, et al. "Privacy-preserving recommendations in context-aware mobile environments." Information \& Computer Security 25.1 (2017): 62-79.

[15] Casillo, Mario, et al. "A Context-Aware Mobile Solution for Assisting Tourists in a Smart Environment", (2017).

[16] Singh, Gnana, et al. "Mobile Application for m-Learning, "International Journal of Advanced Research in Computer Science 8.3”, (2017).

[17] https://in.mathworks.com.

[18] https://edoras.sdsu.edu/doc/matlab/toolbox/fuzzy/. 